Revista de la red interuniversitaria de estudios sobre las literaturas rioplatenses contemporáneas en Francia

$10 \mid 2014$

El XIX en el XX

\title{
El XIX en el XX
}

\section{Cecilia González y Graciela Villanueva}

\section{OpenEdition}

\section{Journals}

\section{Edición electrónica}

URL: http://journals.openedition.org/lirico/1688

DOI: $10.4000 /$ lirico. 1688

ISSN: 2262-8339

Editor

Réseau interuniversitaire d'étude des littératures contemporaines du Río de la Plata

\section{Referencia electrónica}

Cecilia González y Graciela Villanueva, « EI XIX en el XX », Cuadernos LIRICO [En línea], 10 | 2014,

Publicado el 15 marzo 2014, consultado el 22 septiembre 2020. URL : http://journals.openedition.org/ lirico/1688 ; DOI : https://doi.org/10.4000/lirico.1688

Este documento fue generado automáticamente el 22 septiembre 2020

\section{cc) (i) (2)}

Cuadernos LIRICO está distribuido bajo una Licencia Creative Commons Atribución-NoComercialSinDerivar 4.0 Internacional. 


\section{El XIX en el XX}

\section{Cecilia González y Graciela Villanueva}

1 En un célebre poema publicado en El otro, el mismo, Jorge Luis Borges imagina a Sarmiento como alguien que, en 1964, "sigue odiando, amando y combatiendo », es decir alguien que no deja de lanzar, a los argentinos del siglo XX, sus injurias o sus veneraciones. El poema se cierra con un célebre verso que, más allá de la figura que evoca, plasma en forma elocuente esta necesidad de seguir pensando el XIX, o de seguir pensándose desde el siglo XIX : «Sarmiento, el soñador, sigue soñándonos ». Unos veinte años más tarde Ricardo Piglia se pregunta, en Respiración artificial (1980), "¿quién de nosotros escribirá el Facundo?» y uno de sus personajes formula, provocativamente, la definición de Borges como « mejor escritor del siglo... XIX ».

2 Estos ejemplos muestran claramente la importancia de un debate que sigue vigente. Si el siglo XX fue en algún momento un sueño del XIX, la proposición parece también funcionar en sentido inverso: el XIX es, de alguna manera, un sueño del XX, su constante reinvención. La literatura en particular -lo sabemos- ha vuelto incesantemente sobre prácticas y mitos, saberes y discursos, estéticas y personajes decimonónicos. Y ha propiciado, a lo largo de las décadas, los más variados usos estéticos y políticos del pasado. En la narrativa y el cine, en el teatro y en el ensayo, en la poesía y en las artes plásticas del siglo XX y de lo que va del siglo XXI, vuelven autores y personajes (Martín Fierro, Moreira, Artigas, Ansina), temáticas, tópicos, imágenes, discursos y mitos (la pampa, las cautivas, los indios, las luchas entre unitarios y federales o entre colorados y blancos), géneros y estilos (la gauchesca, la literatura gótica, la crónica), ideas y saberes (el espiritismo, la ciencia médica) del siglo XIX. El siglo XX vuelve a los actores y a los tropos, a los territorios y a las fronteras, a las alianzas y a las guerras que, en el siglo XIX, fueron configurando una historia común y construyendo los mitos de una comunidad que se iba inventando a medida que se escribía. Los escritores del siglo XX transformaron aquellos mitos y aquellos sueños en materia de sus ficciones. No sólo Jorge Luis Borges o Piglia sino también, con renovada irreverencia, César Aira, Juan José Saer, Leopoldo Marechal, los hermanos Lamborghini o Andrés Rivera en Argentina, y Eliseo Salvador Porta, Milton Schinca o Mario Delgado Aparaín en Uruguay, por citar sólo algunos nombres. Si en consonancia o en contrapunto con los relatos del XIX se oyeron, a principios del XX, las voces de un 
Ricardo Guiraldes, un Alberto Ghiraldo, un Leopoldo Lugones, un José Zorrilla de San Martín, un Enrique Amorim o un José Enrique Rodó, cien años más tarde resuenan las de Martín Kohan, Carlos Gamerro, Luis Gusmán, Martín Caparrós, Perla Suez, Federico Jeanmaire, Pablo Katchadjian, Oscar Fariña, Alberto Gallo, Diego Fontana, Diego Bracco, Amir Hamed o Jorge Chagas.

El objetivo de este número no es volver a señalar un rasgo que ya ha sido observado y estudiado por la crítica, sino más bien emprender un esbozo de sistematización que no se detenga en 1999 sino que también tome en cuenta las formas en que pervive el XIX en lo que va del siglo XXI. Los artículos, así como los textos de ficción y los testimonios recogidos en este número 10 de Cuadernos LIRICO, plasman la reflexión que una serie de críticos y escritores están llevando a cabo desde esta otra orilla del nuevo milenio y toman también en cuenta algunos de los debates que tuvieron lugar durante los dos encuentros convocados por LIRICO en octubre de 2013 en París y en Bordeaux. Se trata de pensar cómo la literatura rioplatense del XX imaginó o reescribió el XIX, intentar una periodización de las formas que esa mirada sobre el XIX fue adoptando a lo largo del siglo XX y tratar de saber, por último, si ese gesto de incesante reinvención sigue siendo importante para quienes empiezan a escribir y a publicar a principios del siglo XXI.

4 La Argentina inaugura el siglo XX con palabras exaltadas que ponen de relieve su modernidad. Basta recorrer los discursos de celebración del primer centenario de la independencia para constatarlo. Sin embargo, y paralelamente, una de las operaciones fundamentales del nacionalismo cultural del primer tramo del siglo fue, como se sabe, la reivindicación de una tradición rural premoderna y la figura tutelar de Martín Fierro, emblemas de una identidad nacional de criollos viejos que oponer, o proponer, según el caso, a los hijos de la inmigración.

5 Las propuestas de un Rojas o un Lugones nacieron en un contexto en que las consecuencias de la inmigración masiva parecían salirse del control de los grupos hegemónicos. En su intento por identificar una identidad argentina puramente criolla y rural, el nacionalismo privilegió una de las lecturas de la figura del gaucho que el texto de Hernández permitía, pero que estaba muy lejos de ser la única. El gesto de los nacionalistas borraba de un plumazo aquella otra lectura nacida en la prensa anarquista y socialista en las últimas décadas del siglo XIX y en los primeros años del siglo XX cuando, como bien lo observa Tulio Halperín Donghi, la figura de Martín Fierro empezó a aparecer como víctima simbólica de la opresión política y social, un momento en que la oposición entre nativos e inmigrantes perdió fuerza y se vislumbró un ideal de unión de los explotados contra la opresión y los abusos de los dueños del poder ${ }^{1}$, un momento en que, en una línea diferente a la planteada tanto por el nacionalismo como por el socialismo, se reivindicó también la figura de Juan Moreira como expresión de una libertad radical, opuesta a toda negociación y a toda concesión que pudiera limitarla ${ }^{2}$. Por aquellos años, desde las páginas del suplemento cultural del diario anarquista La protesta, también llamado Martín Fierro, Alberto Ghiraldo ensayaba lo que también ensayó en piezas teatrales como Alma gaucha: una apropiación alternativa de la figura del gaucho, en la línea de aquellos rebeldes primitivos que caracterizó Eric Hobsbawm.

6 Desde otro horizonte ideológico, pero confluyendo con estos usos no oficiales, algunos años más tarde Borges encontraría en el ethos guerrero del culto al coraje compartido por el gaucho y el compadrito, un modo de pelearle una tradición nacional al 
patrioterismo y la "lugonería" "3: los héroes de épica popular argentina, y en esto residía para Borges su "misterio parcial", son bandidos antiestatales, "héroes prontuariados"4, criminales y desertores. Las múltiples reescrituras ulteriores de Moreira (por ejemplo las de Perlongher, Fabio, Aira) retomarán, desde diversos lugares y de formas muy variadas, esta dimensión antiestatal que trabó los debates entre moreiristas y antimoreiristas en los comienzos del siglo XX, un fenómeno estudiado por Josefina Ludmer en su trabajo El cuerpo del delito. Un manual, publicado en $19999^{5}$.

7 No es, por cierto, casual que en la década del veinte, cuando los jóvenes vanguardistas publiquen una revista para hacer conocer su producción y sus ideas, elijan llamarla Martín Fierro. Muchos fueron los que, en aquellos años o más tarde, constataron la aparente paradoja, la sutil ironía y la consciente voluntad de disputar a los tradicionalistas un emblema y un símbolo: Martín Fierro simboliza, para los jóvenes artistas de aquella segunda década del siglo XX, al hombre que «de naides sigue el ejemplo ", al que sabe imponer su palabra y su sentir. Y eso es exactamente lo que la vanguardia pretende. Este juego de alianza y tensión entre vanguardia y criollismo es, por otra parte, un rasgo distintivo del escritor martinfierrista: el acento en un arraigo o una pertenencia que los hijos de la inmigración necesitan fortalecer. Aunque con el correr los años se borren los matices, pervive un nombre propio -Martín Fierro, indisolublemente ligado a la tradición nacional- y una certeza: que existe un vínculo indisociable, desde las primeras décadas del siglo XX, entre la modernidad -temida o celebrada- y una activa reelaboración de los relatos y los mitos de la imaginación nacional.

8 Desde el XX, el XIX es percibido como proyecto fundador, "ideología" que pide ser develada como tal, organización de un territorio y de sus fronteras. El XIX se lee desde el XX como un recorte que instauró inclusiones y exclusiones, como un mapa donde se dibujaron las líneas (o zanjas) que limitaban el avance del indio, como una colección de documentos que definieron los lugares de lo que la generación romántica concibió como barbarie o como civilización. Desde el XX, el XIX es percibido también como el momento de redefinición de los "nuevos bárbaros" modernos y urbanos, los que se enfrentaron a los criollos viejos en la novela naturalista del fin del siglo. El XIX se ve también como sinónimo de una historia oficial que celebra un panteón de héroes y que estatuye efemérides patrias. Estas narraciones literarias (naturalistas o románticas), sociales, historiográficas incluso (si se piensa en la historiografía liberal que funda Mitre) definen el horizonte en el que se disputan sentidos y versiones, el marco respecto del cual van a alzarse revisionismos diversos.

9 Aunque el debate se plantee en términos diferentes en el Uruguay -por ser éste un país que en el siglo XIX vivió un complejo proceso de independencia respecto de la colonia y respecto de Argentina (un proceso que comenzó con el llamado Grito de Asencio en 1811 y culminó con la proclamación de la independencia del 25 de agosto de 1825 y la promulgación de la primera constitución nacional el 18 de julio de 1830)-, el siglo XIX no deja de ser una referencia a la que el siglo XX vuelve constantemente. En la década de 1880 Carlos María Ramírez recuperó la figura de Artigas y, aunque su visión del caudillismo haya sido muy distinta de la de un Bartolomé Mitre en Argentina, su trabajo muestra la importancia del XIX para la historiografía uruguaya. A lo largo de todo el siglo XX Uruguay reivindicará su modernidad y en los años 50 llegará a imponer a nivel internacional su imagen de "Suiza de América». Pero el debate no se interrumpe y eso explica que diversos escritores y críticos del siglo XX (Ángel Rama, 
Emir Rodríguez Monegal, Mabel Moraña, Hugo Achúgar, entre muchos otros) hayan insistido, en trabajos muy diversos publicados en diferentes momentos del siglo y hasta hoy, en las complejas relaciones que se establecen entre tradición y modernidad en la orilla oriental del Río de la Plata.

10 La segunda mitad del siglo XX reorganiza los lugares, jerarquías y fronteras de un relato nacional hegemónico, tanto en Uruguay como en Argentina. La discusión de la historiografía liberal iniciada por el revisionismo histórico de ambos lados del Plata a partir de los años 40 se prolonga hasta la ficción de los 60 y $70^{6}$. Las revoluciones de independencia van a proporcionar una matriz narrativa para nuevas emancipaciones. En Los pasos previos de Francisco Urondo, por ejemplo, los conspiradores del presente señalan en el damero de la ciudad de Buenos Aires la jabonería de Vieytes y, a través de ese gesto, resignifican la independencia, o la instituyen incluso, como un proceso de liberación nacional.

11 Para decirlo con términos de Maristella Svampa, la apropiación autorreferencial de la barbarie $^{7}$ marca la cultura política peronista de los 60 y 70 y constituye una forma de intervención en los debates del presente. Cabe recordar, en tal sentido, el gesto que acerca la figura de Facundo a la de Eva Perón de "Esa mujer" o al personaje de Mauricio en "Fotos" de Rodolfo Walsh. Revisar implica revisitar lo que ha sido fijado o establecido, reapropiarse de las dicotomías definidas por el XIX, en particular la de civilización y barbarie (cuyas falencias ya se habían entrevisto antes de que terminara el siglo) y llegar incluso a invertir sus términos. Se trata de empezar a examinar el reverso de las estaturas heroicas, de ver las grietas en la lisura del mármol y el bronce de las estatuas, como lo harán un Viñas en su obra crítica y narrativa o un Andrés Rivera en La revolución es un sueño eterno (1987) o, en Uruguay, un Tomás de Mattos cuando narre el genocidio charrúa a la sombra de una dictadura cuyos ecos resuenan todavía. Se trata, en todos los casos, de reactualizar antiguos relatos, figuras, experiencias (héroes patrios, exilios, persecuciones) para referir oblicuamente nuevos antagonismos.

12 No es seguro que hoy estemos ante usos estrictamente análogos a los que predominaron en los años 1970. Parecería, en todo caso, que la prioridad ya no es denunciar la doxa del XIX, porque hay consenso sobre el hecho de que el XIX es (fue) una construcción. Lo que domina es la impresión de que algunos de aquellos ladrillos pueden servir hoy para hacer otra cosa. El XIX fue fundador no sólo porque impuso un relato hegemónico sino porque inventó una Nación, y en ese sentido se reveló como un poderoso acto de imaginación creadora. Y si buena parte del siglo XX se empeñó en denunciar los supuestos de la ideología que sirvió para preparar ese menú, las últimas décadas insisten no sólo en dar lugar -como lo hicieron los años 70- a los relatos de los vencidos, los excluidos y los invisibles, sino también en dejar oír las voces del sueño, el disparate y el humor, modalidades características de la postmodernidad ${ }^{8}$. El espesor discursivo, o aun narrativo, del pasado entendido como construcción, ha promovido paralelamente el trabajo con planos metanarrativos o metaficcionales, como puede verse con claridad en el interés -que Ricardo Piglia observa en Borges y practica en sus propias novelas- por las tramas narrativas que constituyen a la Nación y a sus sujetos. Por ejemplo "Las actas del juicio" (publicado en Nombre falso en 1975) no es sólo un relato que deja resonar las voces del siglo XIX, sino también una reflexión metaficcional, como el propio Piglia lo reconoce ${ }^{9}$. 
13 Las últimas décadas del XX parecen prolongar, por otra parte, algunas zonas del XIX que antes habían permanecido en la sombra. Y cuando vuelven sobre temas por los que las décadas anteriores ya se habían interesado, lo hacen menos desde el debate ideológico que desde la apropiación (o expropiación) iconoclasta que renueva el gesto vanguardista. Buenos ejemplos de este tipo de trabajo son la reescritura de "El matadero" en "El niño proletario" de Osvaldo Lamborghini (1973), la reescritura de Moreira en Alambres de Néstor Perlongher (1987) o las versiones del desierto, los gauchos y los indios en las novelitas de Aira: en Moreira (un texto escrito y publicado en 1975 pero que sólo pudo circular en la década del 80), y luego en Ema, la cautiva (1981), El vestido rosa (1984), La liebre (1991), El bautismo (1991), El mensajero (1996), Un episodio en la vida del pintor viajero (2000) y, ya en el XXI, Entre los indios (2013).

14 Desde las últimas décadas del XX, el XIX se presenta como el relato que instituyó una lengua común, la lengua de una comunidad: un recorte del mundo, un terreno (una cancha) compartida, una inteligibilidad previa al (o independiente del) posicionamiento de uno $u$ otro actor frente a ella. El XIX aparece menos como una hegemonía naturalizada que como un material, un reservorio de mitos de la imaginación nacional (las cautivas, los charrúas, el caudillo y el gaucho -sobre todo en su versión de bárbaro y rebelde antiestatal-, las Malvinas), de discursos más o menos marcados de anacronismo y ficcionalidad (saberes de la cultura científica y paracientífica del XIX como los que aparecen en los textos de Vecchio, Gusmán o Levrero), de géneros y nombres, de poses o modas a los que los escritores contemporáneos vuelven (un ejemplo es la recurrencia de Mansilla en los textos María Moreno, como bien lo muestra el trabajo de Sandra Contreras, o la novela histórica en la literatura uruguaya de las últimas décadas, como lo evoca Oscar Brando en su testimonio), de figuras y textos canónicos que se prestan a irreverencias y desplazamientos variados (como los que llevan a cabo Pablo Katchadjian, Oskar Fariña, Martín Kohan, Carlos Gamerro, Daniel Guebel o Sergio Bizzio en Argentina y, en Uruguay, Tomás de Mattos, Diego Bracco, Amir Hamed o Martín Bentancor).

15 La noción de literatura menor forjada por Deleuze y Guattari en $1975{ }^{10}$ puede ser útil para comprender el trabajo de muchos escritores argentinos y uruguayos de las últimas décadas. Suele percibirse, en efecto, en la literatura y en la crítica de las últimas décadas, un interés creciente por la consideración de subjetividades minoritarias capaces de poner en tela de juicio la partición de roles de un orden social hegemónico: indios, mujeres... cautivos y cautivas que cuestionan la partición misma, como lo muestra el trabajo de María Angélica Semilla Durán que publicamos en este volumen.

16 Ahora bien, en lo que va del siglo XXI la percepción del pasado parece sufrir una inflexión. Entre lo que el siglo XX identificaba como pasado nacional y el presente se interpone otra época: los años de la dictadura. Son años recientes, pero lo suficientemente distantes para empezar a ser percibidos como historia. Y al mismo tiempo, aunque forman parte del pasado, han sido tan traumáticos que es imposible no tenerlos presentes. Ciertas zonas de esta producción apelan a matrices narrativas que circulan dentro y fuera de los países de la región para narrar las catástrofes y los horrores del siglo XX. Pero dichas matrices (el modelo concentracionario, el relato memorial imbricado con genealogías familiares, el testimonio, la narración de la violencia resignificada como trauma) se modifican cuando se las reutiliza para contar y pensar los años del terrorismo de estado en Uruguay y en Argentina. Porque las narraciones de la violencia política de las últimas dictaduras suelen conjugarse con una 
activa relectura de la tradición nacional. El cisma de la historia reciente no puede sino inflexionar certezas y tradiciones. El XXI no solo discute, desmiente o disputa una lectura del pasado y no solo cuestiona las formas de contarlo, sino que además reorganiza alianzas y enfrentamientos. Se reactivan ecos y se instauran puentes, tanto en la ficción como en la crítica.

17 El número dedicado a la presencia del siglo XIX en el XX está compuesto por ocho artículos, una entrevista, tres testimonios, tres intervenciones filmadas y seis fragmentos de textos de escritores publicados en la última década, además de una sección de novedades y otra de reseñas.

18 Los dos primeros artículos abren la problemática deteniéndose sobre las operaciones críticas de que fueron objeto, en el siglo XX, dos figuras canónicas del siglo XIX: Esteban Echeverría y Lucio V. Mansilla. Cristina Iglesia describe primero cómo nace en el siglo XIX la asociación entre la figura de Esteban Echeverría y la fundación de la literatura nacional y luego revisa las lecturas y los usos de que este escritor ha sido objeto en función de las urgencias y necesidades de las coyunturas políticas del siglo XX. El trabajo de Sandra Contreras se ocupa, por su parte, de trazar el mapa de interpretaciones, reescrituras y usos a los que la literatura y la crítica argentinas han sometido al nombre y a la producción de Lucio V. Mansilla a lo largo de las últimas cinco décadas.

19 Los otros cinco artículos del volumen se detienen en el uso concreto que del siglo XIX hacen los escritores del siglo XX.

20 Pablo Ansolabehere parte del terror como concepto clave en varios de los textos fundacionales de la literatura argentina y del recurso a estrategias y formas de la tradición gótica para narrarlo. Alsolabehere muestra que el cruce entre terror, literatura y política persiste en la literatura argentina del siglo $\mathrm{XX}$, sobre todo en algunos relatos que giran alrededor de la experiencia de la dictadura militar que gobernó la Argentina entre 1976 y 1983. Su análisis se detiene especialmente en dos usos particulares de esa tradición: el que hace Rodolfo Fogwill en Los pichiciegos (1983) y el que hace Martín Kohan en Dos veces junio (2002).

21 Carlos Gamerro estudia algunas de las transformaciones del mito del gaucho Juan Moreira en la producción cultural argentina y para ello recorre la crónica policial, el folletín de Eduardo Gutiérrez, el teatro de los hermanos Podestá y la película de Leonardo Favio, prestando particularmente atención a las lecturas contrapuestas de L. Favio y J. L. Borges y mostrando el modo en que la figura de Moreira entró en el debate político de los años 1970.

22 Alejando Gortázar analiza lo que sucede del otro lado del Río de la Plata con la figura de Ansina, inmortalizado como servidor fiel de Artigas en el relato nacional histórico y mítico. Gortázar parte del análisis del nacimiento literario del personaje, de la mano de Isidoro de María en 1860, evoca luego los debates de historiadores sobre su identidad a lo largo de todo el siglo XX y llega luego a las reescrituras ficcionales de fines del siglo XX y principios del XXI, a cargo de Diego Bracco, Amir Hamed y Jorge Chagas, que constituyen el objeto fundamental de su artículo.

23 Iván Jiménez vuelve a la Argentina, con un análisis de la manera en que El amigo de Baudelaire, novela escrita por Andrés Rivera durante el gobierno de Menem, invierte los sentidos habituales de la dicotomía "civilización y barbarie" y vuelve a la figura de Sarmiento, el "autor de una nación". La confluencia de poesía y prosa representada por 
la figura de Baudelaire da lugar a la problematización de las narrativas del progreso que definen lo nacional en Argentina y al cuestionamiento de ciertas lecturas cristalizadas del pasado nacional.

24 María Angélica Semilla Durán dedica su estudio a la figura de la cautiva y muestra que se trata de un personaje emblemático que recorre los siglos. Las cautivas de los indios reviven en las presas políticas del siglo XX, y aun en esas islas cautivas, las hermanas perdidas, que son las Malvinas. Semilla Durán analiza varias novelas argentinas de las últimas décadas y muestra cómo en ellas se modifican las lecturas simbólicas de las imágenes tópicas de la Nación, cuáles son las inflexiones que se incorporan para colmar los huecos de la representación y qué tipo de imaginario alternativo se dibuja en ese proceso de intervención del mito a través de anacronismos, analogías y recontextualizaciones.

25 La tradición se reescribe también cuando en la literatura de estas últimas décadas aparecen las mujeres cautivas de la trata, figuras que, como lo señalan Nora Domínguez y Gabriela Cabezón Cámara, enlazan tres siglos de violencia de género. La autora de La virgen cabeza, Beya y la recién publicada novela El romance de la negra rubia (véase la sección Novedades) explicita su inscripción en una tradición de narraciones de la violencia a la que "no pued[e] renunciar": La refalosa, El matadero, Martín Fierro, El fjord, Cadáveres, son algunas de sus ocurrencias.

26 La sección "Testimonios" propone una incursión en una crítica en primera persona a la que se prestan Oscar Brando con un artículo sobre sobre la presencia del XIX en la literatura uruguaya del XX, Néstor Ponce con un escrito cuyo título, "El XIX ¿Y yo?", exhibe con precisión las pautas del ejercicio de escritura propuesto y, finalmente, Sergio Delgado, con una versión escrita y ampliada de su intervención en la mesa redonda "Usos estéticos y políticos del pasado en la literatura argentina de hoy", organizada en Bordeaux en octubre de 2013.

27 Las tres intervenciones restantes en dicha mesa redonda pueden verse a través de sus respectivos enlaces. La presentación de Cristina Iglesia vuelve sobre los usos del Martín Fierro en la performance Glosario de la Pampa organizada por el músico Martín Liut a partir de la versión de El Martin Fierro ordenado alfabéticamente de Pablo Katchadjian ${ }^{11}$. El trabajo de Sandra Contreras, Los Martín Fierro del siglo XXI, toma como base, entre otros ejemplos, el mismo texto de Katchadjian y la reescritura "tumbera" que se pone en práctica en El guacho Martín Fierro de Oscar Fariña. La sección se cierra con un trabajo de María Angélica Semilla Durán sobre la persistencia de otras míticas cautivas en las representaciones del cuerpo, mutilado, de la patria y en los relatos contemporáneos sobre la historia reciente: las Malvinas. Su intervención trabaja sobre un corpus de novelas de la guerra que va desde Los pichiciegos de Rodolfo Fogwill hasta Montoneros o la ballena blanca de Federico Lorenz, pasando por Las Islas de Carlos Gamerro.

28 Antes de la sección Reseñas, publicamos en este volumen una serie de fragmentos de textos de ficción, propuestos en su mayoría por sus respectivos autores: Gabriela Cabezón Cámara, Sergio Delgado, Carlos Gamerro, Cristina Iglesia, Néstor Ponce, Diego Vecchio. Se trata de fragmentos de obras publicadas en el siglo XXI (entre 2005 y 2010, para ser más exactos) y en todos ellos la presencia del siglo XIX nos sigue sorprendiendo.

29 Volvamos al poeta para inaugurar la lectura de estos escritos que interrogan la perennidad del XIX a lo largo de las décadas y que, por medio de este mismo gesto, 
participan en la tarea de elaborar una vez más o incluso de instituir, performativamente, un pasado común:

Esas cosas pudieron no haber sido. Casi no fueron:

Las imaginamos

en un fatal ayer inevitable.

No hay otro tiempo que el ahora, este ápice $[. . .]^{12}$.

\section{NOTAS}

1. Sobre las lecturas políticas del gaucho, ver Halperín Donghi, Tulio, « ¿Para qué la inmigración ? Ideología y política inmigratoria y aceleración del proceso modernizador: el caso argentino (1810-1914)» (in: Jahrbuch fur Geschichte Von Staat (Wirschaft und Gesellschaft), Band 13, Koln, Wien : 1976, Bohlau Verlag, p.477, trabajo reeditado en: El espejo de la historia: problemas argentinos y perspectivas latinoamericanas, Buenos Aires : Sudamericana, 1987).

2. Moreira es, en efecto, un personaje que se mueve siguiendo los impulsos de su sentir: dos veces en la novela de Gutiérrez y una vez en la obra de teatro de Gutiérrez/Podestá, Moreira tiene la posibilidad de aceptar un indulto, algo que le permitirá volver a vivir en paz con su familia. Sin embargo, y sin que quede totalmente claro por qué, el gaucho nunca se decide a aceptar lo que percibe como una limitación a su libertad absoluta.

3. Florencia Garramuño estudia "la construcción de una genealogía lineal [en "Historia del tango" de Jorge Luis Borges] en donde el tango y el compadrito vendrían a ser los herederos del gaucho y la gauchesca a través del culto del coraje"; la función esencial de esta operación es la de proponer una "identidad que no se identifica con el Estado", "un nacionalismo cultural que hasta se enfrenta con el nacionalismo de Estado", Modernidades primitivas. Tango, samba y nación, Buenos Aires, FCE, 2007, p. 117. Los términos "patriotero"y "lugonería" son utilizados por Borges en un artículo de la revista Nosotros, año 19, vol. XLIX, núm. 191, abril de 1925 ; el capítulo "Un misterio parcial" de "Historia del tango", da cuenta de la aparente anomalía según la cual, a pesar de contar con un bien provisto repertorio de héroes de las guerras de independencia, de las campañas contra los indios o de guerras civiles, esta épica de transmisión oral elige consagrar la figura del héroe anti-estatal. $C f$. J. L. Borges, Obras completas, Buenos Aires, Emecé,

4. La expresión es de Jorge Rivera en su : «El folletín. Eduardo Gutiérrez ». Historia de la literatura argentina vol. 2. Buenos Aires : Centro Editor de América Latina, 1980. 217-240.

5. Ludmer, Josefina. El cuerpo del delito. Un manual cap. III. Buenos Aires : Libros Perfil, 1999.

6. Sobre las diferencias entre las relecturas de la historiografía liberal en ambas márgenes del Plata, ver el artículo de José Rilla "Revisionismos e izquierdas en Uruguay y Argentina", publicado en Revista Uruguaya de Ciencia Política, vol 19, № 1, enero de 2010, versión en línea (consultada en febrero de 2014) en: http://www.scielo.edu.uy/scielo.php? pid=S0797-97892010000100003\&script=sci_arttext

7. Sobre este tema léase Svampa, Maristella, El dilema argentino : civilización o barbarie. De Sarmiento al pensamiento revisionista, Buenos Aires : Ediciones El Cielo por Asalto, 1994.

8. Utilizamos esta categoría a contrapelo del discurso de quienes recuperan las culturas alternativas, minoritarias, divergentes, periféricas y declaran que la nueva « centralidad » está en los márgenes, pero al mismo tiempo se muestran en los hechos incapaces de escuchar realmente lo que viene de esos márgenes, es decir que utilizamos postmodernidad asumiendo la desconfianza preconizada por intelectuales como Nelly Richard cuando escribe : «... women and the Third 
World are categories more spoken for by postmodernity, without obliging the cultural institution to loosen its discursive monopoly over the right to speak, without ceding to them the much greater right to become autonomous subjects of enunciation, to assume a critical positionality itself capable of intervening (disorganizing) in the rules of discourse that determine property and pertinence (pertenencias $y$ pertinencias). Celebrating difference as exotic festival -a complement of otherness distined to nuance, more than subvert, the universal law- is not the same as giving the subject of this difference the right to negociate its own conditions of discursive control, to practice its difference in the interventionist sense of rebellion and disturbance as opposed to coinciding with the predetermined meanings of the official repertory of difference." (Nelly Richard, "Cultural Peripheries : Latin American and Postmodernist Decentering ", The Postmodernism Debate in Latin America, Boundary 2, vol. 20, no 3, Duke University Press, Autumn 1993, pp. 156-161).

9. Cf. González Álvarez, José Manuel, Formas hibridas y autoficción en la escritura de Ricardo Piglia, Peter Lang, 2009, Anexos, Entrevista a Ricardo Piglia, p. 278.

10. Deleuze, Gilles, Kafka pour une littérature mineure, Paris : Minuit, 1975.

11. Se trata del trabajo Glosario de la Pampa, parte I de Inventarios argentinos. Antes de escuchar la ponencia de Cristina Iglesia, se recomienda ver el fragmento disponible en la página de Martín Liut :

http://martinliut.com.ar/inventarios-argentinos-1-glosario-de-la-pampa-2010-11

12. J. L. Borges, «El pasado », El oro de los tigres, Obras completas, Buenos Aires, Emecé, 1981 [1974], p. 1087.

\section{AUTORES}

\section{CECILIA GONZÁLEZ}

Université Michel de Montaigne Bordeaux 3, SIRENH/ AMERIBER, EA 3656

\section{GRACIELA VILLANUEVA}

Université Paris-Est Créteil, CREER/Imager, EA3958 